\title{
Para pequenos grandes espectadores: a produção televisiva brasileira direcionada a crianças pequenas a partir do caso da Galinha Pintadinha ${ }^{1}$
}

\section{Ariane Diniz Holzbach}

\section{Resumo}

A programação televisiva para crianças vem ganhando contornos de superprodução recentemente, quando espaços como o YouTube abrem novas possibilidades de consumo audiovisual. No Brasil, é possível apontar diversas estratégias desenvolvidas pelas empresas que gerenciam esses conteúdos de forma a atrair um número cada vez maior de público, o que vem reconfigurando todo o circuito comunicativo desse conteúdo. 0 artigo faz um breve histórico da presença dos desenhos na televisão, com destaque para 0 contexto brasileiro, e analisa as estratégias de veiculação de um dos mais famosos desenhos brasileiros direcionados a crianças com até 3 anos: a Galinha Pintadinha. Com isso, foi possível entender a complexificação do circuito que envolve esse tipo de conteúdo e a maneira com a qual novas plataformas, como o YouTube, ajudam a reconfigurar o lugar dos conteúdos audiovisuais infantis.

\section{Palavras-Chave}

Programação Infantil. Desenhos Animados.

Galinha Pintadinha. YouTube.

\section{Ariane Diniz Holzbach}

Doutora em Comunicação pela Universidade Federal Fluminense (UFF), Niterói. Professora adjunta do Curso de Graduação de Estudos de Mídia e do Programa de Pós-Graduação em Comunicação da Universidade Federal Fluminense, (Niterói, Rio de Janeiro, Brasil). E-mail: arianeh@id.uff.br

\section{Introdução}

Nunca se produziu tanto conteúdo audiovisual direcionado para crianças no Brasil como na atualidade. Nos últimos dez anos, esse conteúdo tem crescido em progressão geométrica especialmente quando a popularização de espaços mais flexíveis de veiculação audiovisual, como o YouTube, tornou-se responsável pela distribuição e pelo incrível alcance de muitas dessas produções. Esse fenômeno tem modificado não apenas a linguagem das produções infantis e a relação travada entre elas e as crianças, mas especialmente 0 fluxo de produção e consumo desse conteúdo. Até o início dos anos 2000, por exemplo, embora a programação infantil fosse um elemento expressivo nas grades televisivas brasileiras desde a década de 1960, foi praticamente nula a produção sistemática de desenhos animados no Brasil. As grades televisivas nacionais, por sua vez, foram quase integralmente preenchidas por produções estrangeiras, sobretudo importadas dos Estados Unidos e criadas por gigantes do entretenimento infantil, como Walt Disney e Hanna-Barbera. 
Atualmente, desenha-se um cenário radicalmente diferente, permeado por uma maior produção e, especialmente, pelo enorme e complexo público que consegue atingir. 0 desenho Galinha

Pintadinha é um basilar exemplo desse novo contexto. No mercado midiático desde 2006, ele começou a fazer sucesso após ser desprezado por diversos canais de televisão. De forma despretensiosa, os criadores Juliano Prado e Marcos Luporini publicaram no YouTube o piloto recusado e, meses depois, contabilizaram milhares de visualizações, o que incentivou que criassem e postassem mais vídeos. A Galinha Pintadinha, então, rapidamente se tornou parte importante do entretenimento de uma multidão de brasileirinhos de zero a três anos e uma complexa narrativa transmidiática formada por vídeos musicais, vídeos de histórias, livros, DVDs, brinquedos e mais de 600 produtos licenciados. Diversos vídeos da Galinha Pintadinha atingem, isoladamente, mais de 400 milhões de visualizações, e seu canal oficial no YouTube, que tem mais de 10 milhões de inscritos, foi o primeiro no Brasil a atingir um bilhão de visualizações, em 2014. Desde 2015, a Galinha Pintadinha está disponível na Netflix no Brasil, nos Estados Unidos, no Canadá e em países latino-americanos falantes de espanhol. Dessa forma, um mesmo conteúdo brasileiro pode ser consumido, ao mesmo tempo, em três línguas, em diversas plataformas e em muitos países, o que aumenta expressivamente 0 seu alcance. Ademais, a Galinha Pintadinha foi criada e continua sendo gerenciada pela Bromélia Produções, uma empresa pequena (a despeito de ser milionária) criada exclusivamente para explorar comercialmente a marca Galinha Pintadinha, passando ao largo das televisões hegemônicas tradicionais, formadas pelos canais abertos e por assinatura.

Embora seja o mais famoso, a Galinha Pintadinha está longe de ser um caso isolado. As novas plataformas digitais têm possibilitado que os desenhos animados direcionados a crianças pequenas, historicamente um conteúdo marginal nas televisões, aflore com enorme potencial de propagação. Uma busca rápida no YouTube permite encontrar, por exemplo, uma infinidade de produções estrangeiras dubladas em português, como o canal Kids $T V^{2}$, que em pouco mais de três anos já reúne 500 mil inscritos, além de ser dono de mais de 300 vídeos que, juntos, foram visualizados mais de 300 milhões de vezes. Esses números expressivos repetem-se na produção brasileira disponibilizada na rede, como acontece com os vídeos da formiga azul Bob $Z_{0 o m^{3}} \mathrm{e}$

Uma versão do trabalho foi apresentada no XXVI Encontro Anual da Compós, Faculdade Cásper Líbero, São Paulo - SP, 06 a 09 de junho de 2017.

Link para o Kids TV: https://goo.gl/es8Bkx. Acessado em março de 2018.

Bob Zoom tem um canal oficial que reúne 31 vídeos, mais de 320 mil inscritos e quase 200 milhões de visualizações - e um canal em parceria com a VEVO (BobZoomVEV0) com quase 300 mil inscritos e 250 milhões de visualizações. Criada em 2012 por quatro sócios de uma empresa de Campinas, a SBusiness, a formiga já tem vídeos em inglês, espanhol, coreano e mandarim. Seu material está disponível na Netflix e há uma enorme rede de produtos licenciados para atrair os consumidores mirins. 
do "tiozão" que protagoniza os vídeos

do Mundo Bita ${ }^{4}$.

Esse novo quadro exige, consequentemente, que percebamos de novas maneiras os fluxos contemporâneos dos conteúdos televisivos infantis. Assim, a proposta deste trabalho é contextualizar o desenvolvimento dos desenhos animados focados em crianças de zero a três anos e analisar as estratégias de veiculação desse conteúdo. Para tanto, num primeiro momento, farei um breve panorama da consolidação dos desenhos animados na televisão, com ênfase no caso brasileiro. Em seguida, destacarei a circularidade das produções televisivas e o papel dos conteúdos produzidos à margem da mídia considerada hegemônica. Na última parte, farei uma análise da circulação midiática da Galinha Pintadinha.

\section{Breve panorama dos desenhos animados na TV}

Os desenhos animados historicamente constituem um dos mais abundantes produtos da cultura televisiva, embora, contraditoriamente, sejam os menos contemplados pelas pesquisas científicas (MITTEL, 2013). A sua inserção nas grades de programação teve início na década de 1950, quando a televisão ainda se popularizava em boa parte do mundo, e vem ampliando sua atuação, concretizada atualmente com uma grande quantidade de canais dedicados exclusivamente a eles. Mittell (2003) e Stabile e Harrison (2003) consideram que, inicialmente, a televisão importou animações do cinema - o qual, desde $1908^{5}$, veiculava esse conteúdo antes dos filmes - e as transmitiu de forma aleatória e experimental. Nesse período, desenhos como Popeye e Pica-Pau, criados nas décadas de 1930 e 1940, respectivamente, visando à exploração cinematográfica, foram aproveitados pelos canais televisivos, que precisavam de conteúdos diversificados para preencher horas sem fim de uma programação que ainda se encontrava em processo de formação.

A migração dos desenhos animados do cinema para a televisão, na qual passou a ser produzido e veiculado de forma sistemática, causou uma mudança fundamental para a compreensão do papel cultural desses conteúdos desde então. Nas telas de cinema, os desenhos eram considerados curtas-metragens e desenvolvidos, muitas vezes já de forma serializada, com objetivo de entreter especialmente o público adulto. Ao serem retransmitidos pela televisão, aos poucos, esse mesmo conteúdo foi sendo transformado em "coisa de criança" (MITCHELL, 1995), o que representava um gigantesco grupo de

0 Mundo Bita foi criado no Recife em 2013 e, com canções autorais ilustradas por clipes musicais, tem um canal no YouTube que já atraiu mais de 400 milhões de visualizações e 260 mil inscritos. Além de produzir três DVDs com a Sony Music, 0 Mundo Bita tem contrato com Netflix, Discovery Kids e TV Brasil.

A animação francesa Fantasmagorie é considerada o primeiro desenho animado veiculado em uma sala de cinema. Foi criado por Emile Cohl e transmitido no Théâtre du Gymnase em 17 de agosto de 1908 (STABILE; HARRISON, 2003). 
telespectadores mirins que pouco frequentava os cinemas e que não se importava com a exaustiva reprise de conteúdos que a televisão passou a realizar. Com isso, por exemplo, o linguajar um tanto pecaminoso do Popeye e o mau comportamento crônico do Pica Pau foram modificados à medida que novos episódios foram produzidos para a televisão, de forma a satisfazer mães e pais preocupados com as boas maneiras dos filhos.

Mittell (2004) lembra que os desenhos animados televisivos transformaram-se em sinônimo de conteúdo infantil, de tal forma que, nas grades de programação estadunidenses, desde os anos de 1960 e por várias décadas, instalaram-se hegemonicamente aos sábados de manhã. 0s objetivos das emissoras eram 1) preencher um horário que até então trazia poucos lucros com publicidade e 2) fazer com que os desenhos fossem mais facilmente consumidos pelas crianças, que não iam para a escola nesse dia e, ao mesmo tempo, podiam ter o conteúdo a que assistiam vigiado pelos pais.

Com a consolidação dos desenhos nas grades televisivas, duas grandes produtoras ascenderam: a The Walt Disney Company e a Hanna-Barbera. A primeira foi fundada em 1923 e, ainda no "período cinematográfico dos desenhos" (BARRIERS, 1999), foi responsável por desenvolver variadas técnicas para industrializar a elaboração das animações. 0 fundador, Walter Elias Disney, desenvolveu mecanismos para tornar possível que diferentes artistas desenhassem os mesmos personagens com o mesmo tipo de traço, além de compartimentar a produção (separando os roteiristas dos desenhistas, por exemplo), privilegiar a história em detrimento do traçado e adotar a chamada cel technique, na qual os desenhos são feitos em camadas de modo a terem seus elementos reaproveitados em histórias futuras. A mecanização possibilitou a consolidação dos desenhos na televisão tendo em vista a necessidade de produção rápida e em larga escala, advinda principalmente da lógica da grade de programação.

A Hanna-Barbera, diferentemente, surgiu já no contexto da cultura televisiva. Criada em 1957 pelos cartunistas William Hanna e Joseph Barbera, a empresa tornou-se uma das mais especializadas em desenhos animados televisivos. A dupla criou uma enorme quantidade de personagens que ainda transitam por televisões ao redor do mundo -Tom \& Jerry, Manda Chuva, Scooby-Doo, Zé Colmeia, Jonny Quest e centenas de outros - e, para otimizar a distribuição desse conteúdo, sofisticou os mecanismos de reprodutibilidade técnica. Além de trabalhar com gráficos simples, compostos por cenários, em grande medida, estáticos e monocromáticos (Figura 1), e conceder ênfase aos diálogos, a empresa popularizou os desenhos feitos com repetição cíclica de movimentos, repetição constante do fundo e pequeno repertório de gestos e expressões. Essas estratégias aceleraram exponencialmente a produção, possibilitando que um único desenhista fosse responsável por uma grande quantidade de ambientações e personagens. 
Figura 1: Fundo estático e monocromático em episódios do Scooby-Doo (1969-)
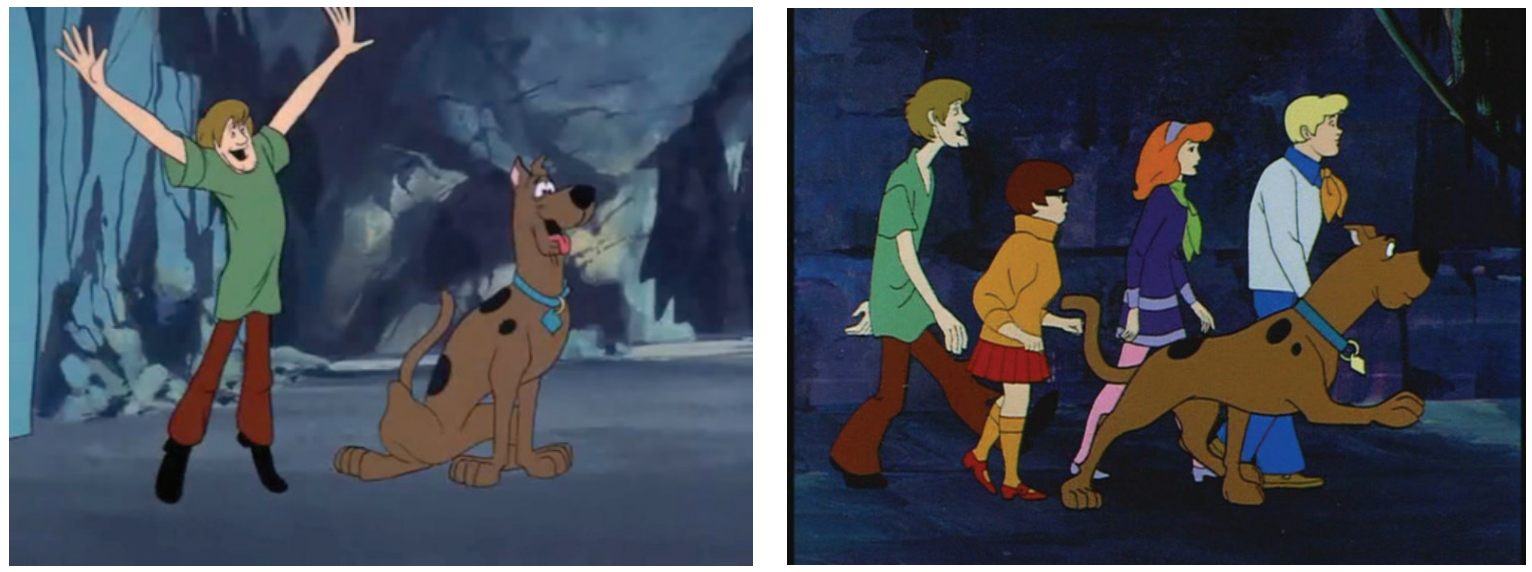

A partir da década de 1960 e por mais de 30 anos, a Hanna-Barbera foi quase onipresente na programação televisiva infantil ocidental ${ }^{6}$. Seu poder simbólico cresceu tão rapidamente que, em 30 de setembro de 1960, levou ao ar 0 primeiro desenho animado televisivo direcionado para adultos, transmitido em horário nobre. Tratada como sitcom, a série Os Flinstones foi veiculada por seis anos pela $\mathrm{ABC}$, em episódios de 30 minutos, à noite, e houve especial atenção aos anúncios publicitários. Em 1961, a "sitcom" chegou a ser indicada ao Emmy na categoria de série de humor, legitimando esse desenho como conteúdo adulto "de qualidade". Os Flinstones abriram portas para outras experiências animadas voltadas para os adultos, como Os Jetsons (19621963, também da Hanna-Barbera) e, a partir de 1989, Os Simpsons, veiculado pela Fox e uma das

mais longas "séries" televisivas da história. 0 seu legado é balizado por várias pesquisas científicas, as quais apontam diversificadas inovações, relacionadas à narrativa e ao mercado televisivo, que esse desenho ajudou a consolidar (ALTERS, 2003; B00KER, 2006; MITTELL, 2001).

Na década de 1980, a cultura televisiva tinha em grande conta a programação infantil, 0 que incentivou o surgimento de produtoras de animação e de novos personagens que deram um caráter cultural e economicamente mais heterogêneo à oferta desse conteúdo. A partir de uma regulamentação estadunidense que permitiu, a partir de 1980, a produção de desenhos animados televisivos baseados em brinquedos (PEREA, 2015), o mercado ocidental transformou esse consumo em uma experiência 
ampliada que movimentou outros setores da economia. Nesse período, foi comum o surgimento de desenhos criados para vender produtos a eles adjacentes, como bonecos, jogos e toda sorte de produtos infantis. Esse foi particularmente 0 caso de fenômenos de audiência televisiva ocidental como He-Man e os Mestres do Universo (1983-85 / 1988-1990), She-Ra: A Princesa do Poder (1985-87), Transformers (1984-1987), ThunderCats (19851990) e Meu Querido Pônei (1986-1987).

Nesse período, um importante contraponto em relação à lógica de produção estadunidense foi o desenvolvimento, no mercado ocidental, dos animes. A produção japonesa de animação, que se desenvolvia avidamente nesse país desde a década de 1960 na televisão, chamou atenção de um significativo grupo de jovens (URBANO, 2013), atuando como uma opção alternativa ao hegemônico modelo Hanna-Barbera. A popularização do videocassete, ocorrida também nesse período, foi fundamental para a eficiente distribuição desse material no mercado estadunidense. Alguns animes atraíram muita audiência em países ocidentais, como Astro Boy (1952-63), Cavaleiros do Zodíaco (1986-90) e Pokemon (1997-). Se, inicialmente, a produção de animes foi bastante inspirada em desenhos animados ocidentais consumidos pelos japoneses, como a produção da Disney, aos poucos a produção nipônica passou a exercer influência sobre os desenhos estadunidenses.
Aliado 1) à popularização dos desenhos animados conectados a uma ampliada cultura do consumo e 2) à popularização dos animes no Ocidente, há que se considerar também a instituição global da televisão por assinatura. Embora se desenvolvesse nos Estados Unidos desde especialmente a década de 1960, nos anos de 1990 a tecnologia a cabo se espalhou pelo mundo. Os desenhos encontraram um espaço fértil na televisão segmentada, responsável por oferecer múltiplos canais com a mesma temática que, destarte, atraía públicos cada vez mais específicos. Este foi o caso de canais como Nickelodeon, Disney Channel, Discovery Kids, Cartoon Nerwork, Nick Jr., Tooncast, Disney Jr., Boomerang, Baby TV e, no Brasil, também o Gloob. Em comum, esses canais atuam até hoje veiculando uma enorme quantidade de desenhos animados, incluindo programações da sede estadunidense e também de outros países, numa contínua estratégia de solidificação em espaços geográficos variados a partir de uma junção entre conteúdos globais e locais (SANDLER, 2013; WAISBORD, 2004). Talvez o sucesso desses canais tenha levado à significativa redução dos desenhos animados e da programação infantil de maneira geral das televisões abertas a partir dos anos 2000, pelo menos no caso brasileiro.

\section{Desenhos animados na TV brasileira}

Embora 0 início da produção animada brasileira tenha se dado precocemente ${ }^{7}$, o país nunca 
conseguiu manter uma produção sistemática, que atendesse à demanda massiva das emissoras de televisão. Diferentemente do que ocorreu com outros conteúdos, como as telenovelas, o Brasil desenvolveu uma produção tímida de desenhos por décadas a fio. Isso pode ser explicado especialmente pela dificuldade em investir nesse mercado, de alto custo e mão de obra extremamente especializada, e pelo interesse das corporações internacionais em escoar sua produção. As emissoras abertas dedicaram espaço significativo aos desenhos, mas optaram quase inteiramente por produtos importados, os quais já haviam sido testados em outros países, como as produções da Disney, da Hanna-Barbera e dos animes. A única exceção a essa regra é a TV Brasil, que historicamente dedica parte importante de sua grade à programação infantil e à produção brasileira de desenhos animados, com ênfase na busca pela urgente inserção dos conteúdos infantis nas políticas públicas de comunicação (SAMPAIO, CAVALCANTE, 2012). No contexto da televisão aberta brasileira, trata-se de uma emissora que cumpre papel fundamental de inclusão das crianças como consumidoras de produtos midiáticos e, também, como cidadãs.

Até a década de 1970, a inserção dos desenhos na televisão brasileira aconteceu sobretudo em duas frentes. De um lado, houve a compra de desenhos de grandes produtoras estrangeiras para veiculação em diferentes horários. Inicialmente (e como ocorre, ainda, em alguns casos), não havia preocupação com a possível serialidade dos episódios, e a reprise já era realidade. Em 1975, por exemplo, a TV Rio exibia Popeye, Os Jetsons e o Programa Turma da Pesada, dedicado a desenhos. A Rede Globo, por sua vez, nesse mesmo ano exibiu pelo menos dois programas com desenhos: Banana Split e Festival de Desenhos ${ }^{8}$. De outro lado, o crescente mercado publicitário televisivo permitiu a produção de diversos comerciais animados, além da criação de mascotes para grandes marcas, como foi 0 caso da Barata Rodox (1971) $)^{9}$ que tinha pavor do inseticida de mesmo nome, e do Homenzinho Azul $(1978)^{10}$, criado para os cotonetes Johnson \& Johnson (Figura 2). 


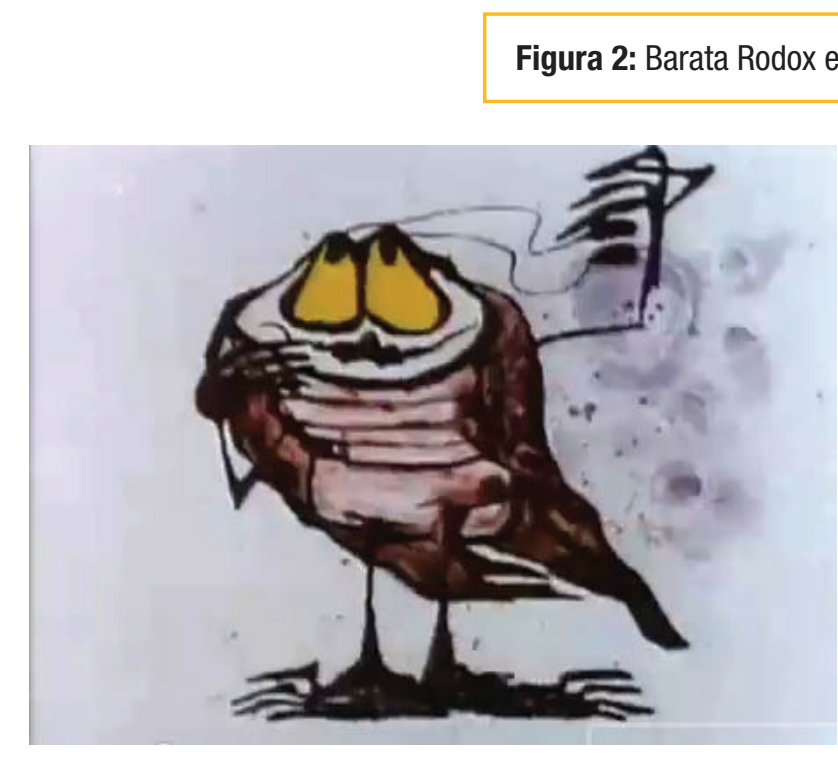

Com a boa aceitação desse conteúdo pelos telespectadores brasileiros, as grades de diferentes canais foram aglutinando os desenhos em programas específicos. Com isso, na década de 1980, uma fórmula reproduzida em variadas emissoras se consolidou: os programas infantis de auditório. Eles eram comandados por crianças e/ ou adultos que se encarregavam de "apresentar" os desenhos, além de organizar brincadeiras e competições para entreter uma plateia repleta de crianças. A Globo, por exemplo, explorou exaustivamente esse tipo de conteúdo com programas como A Turma do Balão Mágico (1982-1986) e, sobretudo, o Xou da Xuxa (19861992). 0 sucesso deste último foi tão grande que chegou a ser veiculado por cinco horas consecutivas, de segunda a sábado, numa época em que a Globo já era a mais forte emissora do país. Outras emissoras produziram variações desse tipo de programa, como Show Maravilha (SBT, 1987-1994), Oradukapeta (SBT, 19871990), Clube da Criança (Manchete, 1983-

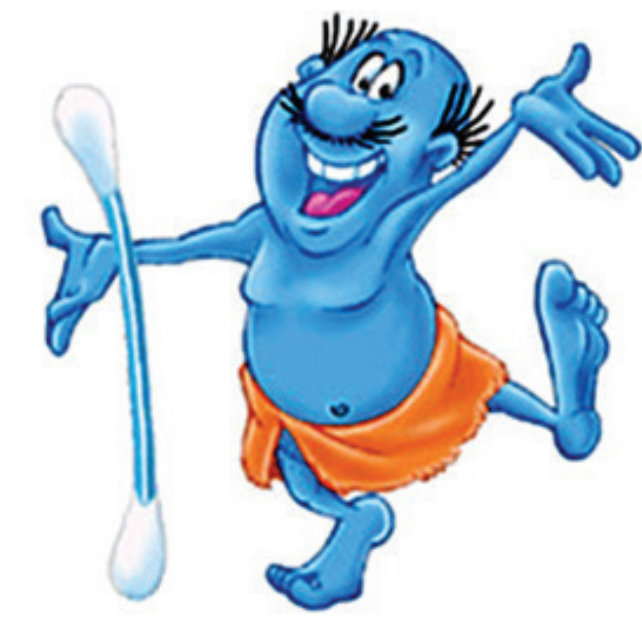

1998) e Nave da Fantasia (Manchete, 1987).

Além de fortalecerem a presença dos desenhos animados estrangeiros nas grades brasileiras, esses programas ajudaram a consolidar no país, especialmente, os desenhos baseados em brinquedos, os quais, em muitos casos, repetiram o sucesso alcançado no exterior.

Os programas infantis de auditório também ajudaram a popularizar os animes, que tiveram presença na televisão brasileira especialmente entre as décadas de 1980 e 1990. Diferentemente do que ocorreu nos Estados Unidos, onde os animes só encontraram espaço nos anos de 1980, o Brasil veiculava parte desse material já na década de 1960 , como foi o caso de 0 Oitavo Homem, exibido pela Globo em 1968 (MONTE apud URBANO, 2013). Nas décadas de 1980 e 1990, todavia, os animes preencheram boa parte das grades televisivas da Manchete, por exemplo, em que Cavaleiros do Zodíaco começou a ser exibido em $1^{\circ}$ de setembro de $1994^{11}$ e atraiu uma significativa audiência jovem. 
A partir de 1991, com a entrada da televisão por assinatura no Brasil, o fluxo dos desenhos sofreu um processo de reconfiguração, considerando que a entrada dos canais transnacionais dedicados à programação infantil movimentou esse mercado. Sugere-se que os canais por assinatura dedicados às crianças podem ter acelerado o processo de saturação dos programas infantis de auditório, ocorrido ao longo da década nas emissoras brasileiras, uma vez que muitos desses canais são comandados pelas empresas transnacionais que, até então, vendiam os desenhos para as emissoras brasileiras. Embora algumas emissoras ainda dediquem parte de sua grade à programação infantil, na maior parte dos casos essa programação é preenchida ou por programas importados que mesclam desenhos e seriados (como Mundo Disney, veiculado pelo SBT) ou por programas de estúdio, com atuação de adultos e crianças, mas sem 0 caráter de auditório instituído nos programas anteriores (como Parque Patati Patatá, também exibido pelo SBT).

Além disso, a valorização da programação de nicho evidenciada com a televisão por assinatura possibilitou que algumas emissoras brasileiras também se tornassem proprietárias de canais dedicados às crianças. A Globosat, nesse sentido, criou, em 2012, o Gloob, concorrente dos canais infantis transnacionais. Embora também veicule desenhos importados e reprises de "clássicos", como Popeye, He-Man, Smurfs etc., o canal vem investindo em produções próprias, o que, em última instância, tem incentivado a produção sistemática de desenhos brasileiros, a exemplo de Osmar, a Primeira Fatia do Pão de Forma (2010-), Tronquinho e Pão de Queijo (2015-) e SOS Fada Manu (2015-). Nesses casos já existe, por parte do canal, a preocupação com a serialidade, além de um cuidado maior com as reprises e com outros elementos do circuito comunicativo dos desenhos contemporâneos, como a cultura fã. A popularização da internet, nesse sentido, oferece novos elementos para fortalecer e problematizar a presença e o fluxo dos desenhos animados brasileiros na televisão, como será analisado a seguir.

\section{Fluxos dos desenhos televisivos contemporâneos}

0 desenvolvimento das tecnologias midiáticas, aliado à popularização da cultura digital, vem ocasionando uma miríade de reconfigurações em todas as esferas audiovisuais. No que concerne aos fluxos dos conteúdos televisivos, essa reconfiguração pode ser parcialmente compreendida a partir de duas frentes complementares. De um lado, como destacam Banks (1996, 2005), Bulck e Enli (2014) e Waisbord (2004), entre outros, o século XXI assiste ao fortalecimento dos conglomerados midiáticos. Resultantes especialmente do processo de globalização intensificado a partir da 
década de 1980, os conglomerados cada vez mais têm ampliado seu campo de atuação para todas as esferas midiáticas possíveis. De outro lado, o desenvolvimento das tecnologias midiáticas e da cultura digital potencializaram o surgimento e fortalecimento de novos atores que estão, em muitos casos, fora do eixo norte-americano e europeu e conseguem espalhar sua produção para além de sua cultura local. É 0 caso do audiovisual na Nigéria e em Gana, como apontam Haynes (2010) e Saul e Austen (2010). Através de uma tecnologia de baixo custo, esses países têm desenvolvido uma massiva produção que, nos últimos 20 anos, tem "transformado 0 ambiente audiovisual na África” (HAYNES, 2010, p. 11), além de chegar à Europa junto com a imigração africana. Um fenômeno adjacente ocorre na Nova Zelândia, cuja televisão tem passado por radicais transformações a partir da entrada da TV a cabo, em 1990. Embora o país consuma uma grande quantidade de conteúdos provenientes dos conglomerados, a cultura nativa, formada pelos Maoris, tem aumentando sua atuação na televisão (HORROCKS, 2004).

No que concerne aos desenhos animados, essas duas frentes - fortalecimento dos conglomerados e valorização das produções geograficamente à margem do circuito midiático hegemônico - têm atuado a favor dos conteúdos locais. Isso acontece especialmente porque as grandes televisões têm apostado numa mistura entre conteúdos globais e locais como estratégia de fortalecimento e ampliação de mercado (WAISBORD, 2014). No Brasil, alia-se a isso o fato de que, desde a instituição, em 2011, da Lei 12.485, a Lei do Cabo, os canais especializados em séries, filmes e desenhos são obrigados a transmitir pelo menos 3,5 horas semanais de produções brasileiras durante o horário nobre. Assim, por exemplo, 0 Cartoon Network dedicou cerca de 15\% de sua programação diária às produções brasileiras em $2015^{12}$. Um dos desenhos de maior sucesso na filial nacional é Irmão do Jorel (2014-), criado pelo capixaba Juliano Enrico em parceria com o Cartoon. Além desse, a programação brasileira do canal conta com vários desenhos nacionais, como Turma da Mônica, Historietas Assombradas (para Crianças Malcriadas), Gui \& Stopa e Tromba Trem. Ademais, fazem parte da programação algumas produções de fora do circuito tradicional (representado principalmente por Estados Unidos, Canadá e Japão), a exemplo da produção russa Masha e o Urso e da produção de Singapura ODDBODS.

Muitas vezes, alguns desses desenhos ampliam sua experiência de fruição para variadas mídias e contam com um, cada vez mais, apaixonado grupo de fãs (mirins) que, como afirma Jenkins (2009), vai a todos os lugares em busca do entretenimento que almeja. Sites, fanpages, episódios extras, making ofs, crossovers, fóruns de discussão, fanmades e aplicativos 
para celular, por exemplo, constroem uma narrativa transmidiática que reconfigura a expectatorialidade desses conteúdos e, finalmente, leva o consumo dos desenhos para além do aparelho televisivo convencional. 0 potencial que os desenhos apresentam em "sair" da televisão pode ser observado na maneira como novas plataformas audiovisuais têm manipulado esse conteúdo, como a Netflix e, finalmente, o YouTube.

De maneiras diferentes, Netflix e YouTube reconfiguram o consumo televisivo ao oferecerem experiências relacionadas com a televisão, mas com novos modelos de negócios centrados no deslocamento da lógica da grade de programação (MASSAROLO; MESQUITA, 2016). Embora exista um leque previamente definido de programas, estes podem ser acessados em qualquer horário e em plataformas audiovisuais que não dependem, por exemplo, de concessões públicas para expor esse material. Sob a categoria intitulada "Animação", a Netflix explora uma gama ampliada de desenhos em relação ao que é ofertado pelos canais televisivos: 1) reprises de produções antigas da Disney, Hanna-Barbera etc.; 2) desenhos já exibidos pelos canais, mas que estão fora da programação televisiva; 3) produções atualmente exibidas pelos canais televisivos; 4) desenhos animados "originais"; 5) desenhos animados de produtoras brasileiras e internacionais que jamais tiveram entrada na televisão brasileira.
0 YouTube, por sua vez, também oferece um ampliado leque de desenhos em relação à televisão convencional, mas assumindo uma lógica diferente, que evidencia a cultura participativa por meio da possiblidade de manipulação de conteúdos comandada, em grande medida, por atores não institucionalizados, como as pessoas "comuns" (BURGESS; GREEN, 2009; SHIFMAN, 2011). Nesse sentido, o YouTube tanto reúne material disponibilizado pela "grande mídia" como incentiva as publicações realizadas por pequenos produtores e pessoas sem vínculo com empresas. Esse fenômeno altera profundamente a experiência de consumo dos desenhos animados (e de quaisquer conteúdos ali ofertados) na medida em que exclui, em princípio, parte dos filtros tradicionais de seleção de conteúdo (dos quais a Netflix é parcialmente devedora). Ademais, o YouTube reconfigura o circuito comunicativo desses conteúdos considerando que, além dos desenhos per si, o site veicula fragmentos de conteúdos fora de seus contextos de origem (por exemplo, uma única cena de um desenho qualquer) e inúmeros paratextos desses desenhos, que, muitas vezes, como lembra Jonathan Gray (2010), transformam-se em textos com boa dose de autonomia em relação à produção a que se vincula originalmente. Ademais, o YouTube possibilita que conteúdos originais, independentemente de quem seja o produtor, ganhem visibilidade e se profissionalizem (LOBATO, 2016; MORREALE, 2014), alterando a dinâmica desses conteúdos e modificando o jogo político existente em torno das decisões sobre que tipo de programa/ 
conteúdo deve ou não ser exposto ao público. Esse fenômeno é particularmente evidenciado com a história de criação e popularização dos vídeos da Galinha Pintadinha.

\section{0 caso da Galinha Pintadinha}

\section{A Galinha Pintadinha pode ser entendida} como uma experiência inaugural. Quando surgiu, em 2006, o YouTube tinha apenas um ano e era preenchido principalmente com conteúdo audiovisual não institucionalizado e não profissional. 0s criadores, Juliano Prado e Marcos Luporini, tentaram "emplacar" o material nas emissoras de televisão, mas estas estavam ainda largamente dependentes da produção internacional, como já analisado. Apenas após ser recusada pelas emissoras, a dupla publicou um dos vídeos no YouTube, e o sucesso, inicialmente, aconteceu de forma espontânea, sem uma estratégia atrelada à publicação. Em seis meses, o vídeo Galinha

Pintadinha - videoclip infantil animado ${ }^{12}$ alcançou 500 mil visualizações, o que levou os empresários a criarem uma produtora, a Bromélia Produções, a desenvolverem mais episódios e a escolherem, entre as personagens, a Galinha como protagonista (PINHO; ROCHA, 2015).

Os vídeos da Galinha Pintadinha ilustram, por meio de canções e cenários alegres, sentimentos e ações simples que fazem parte do cotidiano da maioria das crianças. Escovar os dentes, ir para cama à noite, almoçar, dançar, brincar, fazer amigos e outras situações são exploradas através de diversos personagens. A protagonista é uma ave azul casada com o Galo Carijó, mãe de vários pintinhos amarelinhos e amiga de muitas personagens inspiradas nas cantigas de roda brasileiras, como o Sapo, a Formiguinha, a

Figura 3: A família da Galinha Pintadinha e as quatro crianças amigas da Galinha
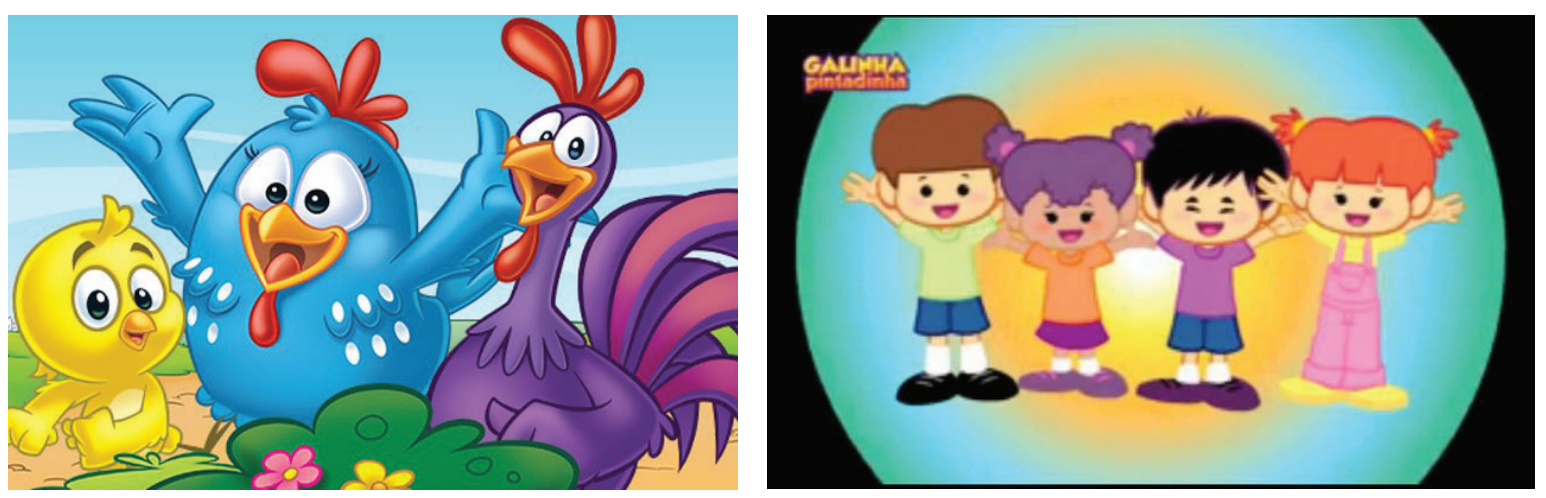
Borboletinha e a Dona Aranha. A Galinha

e a família vivem na fazenda do seu

Lobato, onde também moram a Vaquinha,

0 Gato e o Cachorro, e têm quatro amigos

humanos, que são um grupo de crianças que

representam diferentes etnias (Figura 3).

Os desenhos são integralmente musicados, e as ações realizadas têm forte apelo didático.

Em termos estéticos, a despeito da avançada tecnologia 3D existente e dos softwares contemporâneos de animação, os desenhos são em 2D e apresentam fundo estático e com poucos elementos, reproduzindo parte do modelo consolidado pela Hanna-Barbera. São priorizadas as cores fortes e 0 traço simples para chamar a atenção dos pequenos, além de, recorrentemente, reaproveitarem-se cenas e coreografias em diferentes vídeos, numa tentativa de simplificar a técnica para acelerar a produção (Figura 4).
Como ocorre com os videoclipes, cada vídeo tem uma única canção, cujo título é também o título do vídeo, e as imagens com frequência descrevem a letra. Esta, por sua vez, é feita quase integralmente com base em canções infantis que estão em domínio público, como O Sapo não lava o pé, Atirei o pau no Gato, Ciranda Cirandinha, Pintinho Amarelinho, Borboletinha etc. Essa estratégia, inclusive, é utilizada por outros desenhos, para crianças pequenas, que fazem sucesso na Internet e, além do barateamento da produção, também oferece um produto bastante reconhecível pelas crianças, que ouvem canções semelhantes na escola, cantada pelos avós, em festas infantis e outras situações ${ }^{13}$.

\section{Plataformas de veiculação da Galinha Pintadinha}

0 canal criado no YouTube ${ }^{14}$ foi a principal impulsionadora do sucesso que a Galinha

Figura 4: À esquerda, frame de Pai Francisco. À direita, frame de Noite de São João
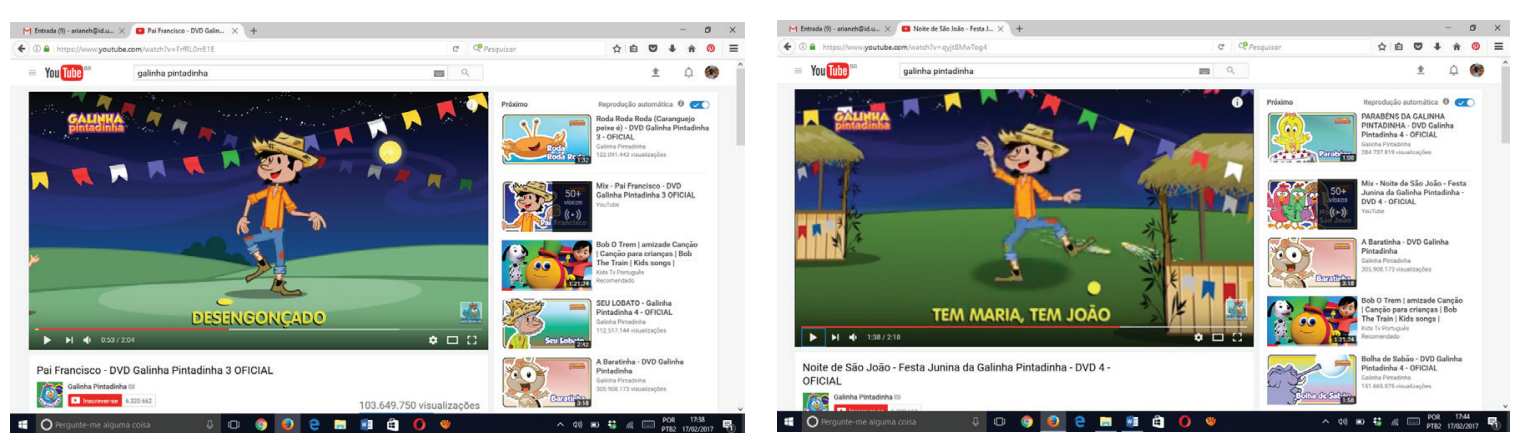

13 Bob Zoom, por exemplo, também tem em seu leque de vídeos as canções Pintinho Amarelinho e Borboletinha, além de outras cantigas conhecidas como Noite Feliz e Os Dedinhos. 
Pintadinha alcançou desde a estreia. Além de servir como um espaço fundamental de consumo, divulgação e compartilhamento dos episódios, os empresários passaram a receber do site quantias significativas em dinheiro à medida que os vídeos alcançavam números crescentes de visualização. Ainda em 2006, quando surgiu, os vídeos da (agora chamada) série ultrapassavam 15 milhões de visualizações por dia e começaram a ser pauta de jornais e revistas. Em 2008, foi lançado o primeiro dos quatro DVDs existentes, o que possibilitou acesso aos vídeos em plataformas off-line e ampliou, com isso, as possibilidades de consumo do material. Em 2010, quando quase todos os pais de bebês brasileiros já sabiam as canções de cor, a Galinha Pintadinha finalmente chamou atenção da grande mídia: uma parceria firmada com a major Som Livre (pertencente ao Grupo Globo) lançou o segundo DVD da série. Só no primeiro mês, foram vendidas 100 mil cópias, um número alto considerando o consumo gratuito do mesmo conteúdo oferecido pelo YouTube. Em 2012, o primeiro e o segundo DVDs contabilizavam, juntos, mais de 330 mil cópias vendidas, e 0 terceiro DVD, que acabara de ser lançado, já tinha vendido 150 mil cópias ${ }^{15}$.

A estratégia seguinte de popularização da Galinha Pintadinha ocorreu em 2011, quando a Bromélia
Produções firmou contrato com a tradicional agência de licenciamento Redibra e começou a desenvolver produtos inspirados nas personagens dos vídeos através de mais de 60 fabricantes. Em cinco anos, o desenho já tinha mais de 600 produtos a ele vinculado. Em 2015, a Galinha Pintadinha teve mais produtos licenciados do que a Volkswagem e a Sony Picutres e chegou a ficar na $89^{\circ}$ colocação entre as empresas que mais vendem produtos no mundo - a melhor colocação de uma empresa brasileira ${ }^{16}$. Além de dezenas de brinquedos, há alimentos, produtos para bebês, vestuário, calçados, produtos de higiene pessoal, eletrônicos, papelaria, produtos de cama, mesa e banho, editorial, material para festas e utensílios variados. Entre as fabricantes desses produtos, há marcas como C\&A, Grendene, Danone, Renner, Cremer e Unilever, o que fez com que o faturamento da Bromélia Produções alcançasse 300 milhões de dólares em produtos em $2015^{17}$.

Finalmente, em 2012, o desenho iniciou sua carreira internacional. Mais uma vez o YouTube foi a primeira ferramenta acionada: foram criadas versões em inglês ${ }^{18}$, espanhol ${ }^{19}$, italiano $0^{20}$, francês ${ }^{21}$ e japonês ${ }^{22}$ do canal, além da tradução para essas línguas de algumas canções. À medida que os vídeos atingiam bons índices de visualização,

14 Disponível no link: https://goo.gl/wSfdWZ. Acessado em março de 2018.

15 Informações retiradas do link https://goo.gl/iA15WW. Acessado em março de 2018.

16 Ranking feito pela revista inglesa Licence! Global. Informações retiradas do link https://goo.gl/mtfj5N. Acessado em março de 2018. 
o que aconteceu inicialmente com a versão em espanhol, a agência Redibra foi firmando contato com empresas dos países de onde vinha o grosso das visualizações, como o México. Ainda como estratégia de internacionalização, em 2012, a Galinha Pintadinha estreou na Netflix brasileira e, posteriormente, nas versões estadunidense, canadense e nos países latinoamericanos falantes de espanhol. A partir de 2013, a Bromélia Produções continuou produzindo vídeos animados e DVDs, além de ser um dos destaques brasileiros da Netflix, de forma a tentar consolidar sua carreira internacional. Em 2016, a Bromélia Produções criou o spin off Galinha Pintadinha Mini; um grupo de vídeos com narrativas de menos de cinco minutos em que as personagens da Galinha Pintadinha aparecem na versão "mini". A estratégia de consolidação desse material seguiu a trajetória da versão original: canal no YouTube, site oficial com muitos produtos à venda, DVD com todas as histórias e muitos vídeos disponíveis gratuitamente para serem compartilhados (Figura 5).
Figura 5: Primeiro spin off: a Galinha Pintadinha Mini

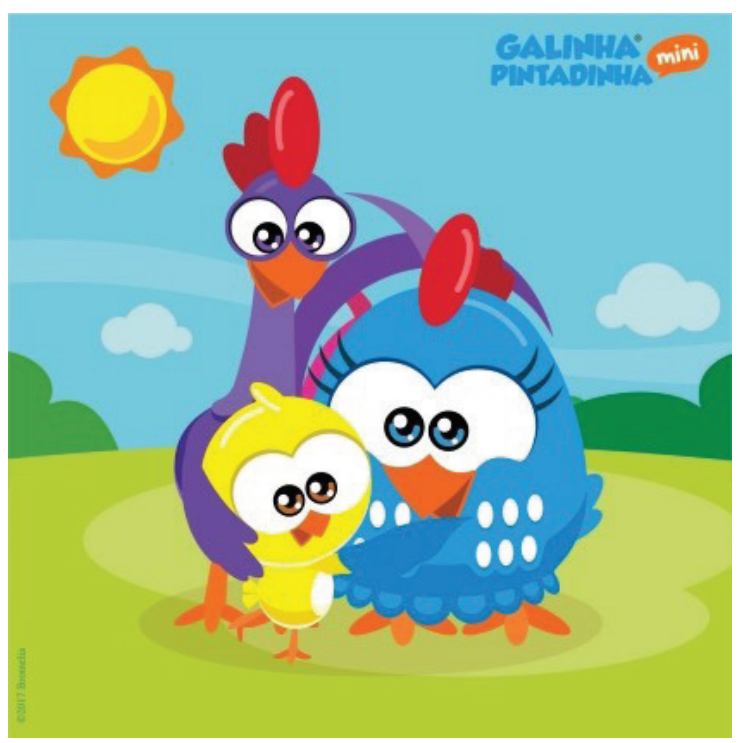

Por fim, convém ainda destacar a fanpage da Galinha Pintadinha ${ }^{23}$, que tem quase 4 milhões de inscritos e atua como uma vitrine publicitária e de interação com o público. № espaço, há compartilhamento de vídeos do YouTube e divulgação de lançamentos de produtos licenciados, além de eventos que tenham a participação da Galinha, como espetáculos teatrais e festas infantis (feitos por atores fantasiados). Chama atenção a quantidade de

18 Canal disponível no link https://goo.gl/3yMAqC. Acessado em março de 2018.

19 Canal disponível no link https://goo.gl/ZTcWMR. Acessado em março de 2018.

20 Canal disponível no link https://goo.gl/BoqzSk. Acessado em março de 2018.

21 Canal disponível no link https://goo.gl/DiqVUg. Acessado em março de 2018.

22 Canal disponível no link https://goo.gl/sijDcm. Acessado em março de 2018.

23 Fanpage da Galinha Pintadinha: https://goo.gl/1iqkC8. Acessado em março de 2018. 
Figura 6: Fotografias publicadas na fanpage da Galinha Pintadinha (rostos ocultados pela autora)

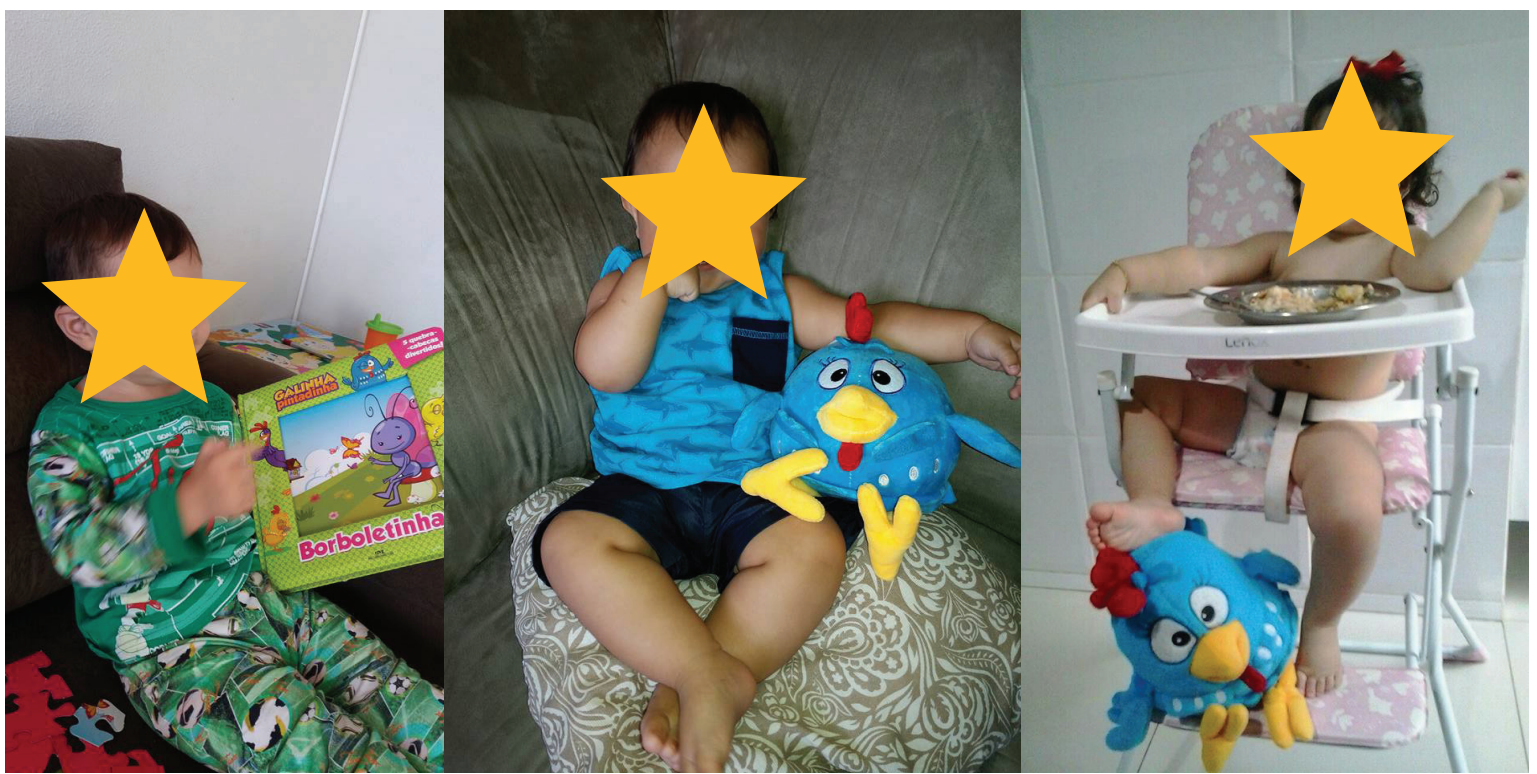

pais e responsáveis que enviam fotografias de suas crianças interagindo com o desenho (Figura 6). Além da exposição visual que as fotografias causam em torno dessas crianças, em muitos casos, as legendas fornecem informações detalhadas, como nome completo, idade, cidade onde reside e rotina. Em outros casos, há informações provavelmente exibidas sem intenção, como o uniforme escolar, detalhes do mobiliário do quartinho, de refeições e de muitos outros elementos que fazem parte da vida privada da criança.

\section{Considerações finais}

0 universo midiático em torno das crianças pequenas é onipresente, mas as pesquisas em Comunicação ainda pouco se debruçam sobre esse vasto império. A maior parte das reflexões que tratam da relação entre mídia e crianças restringe-se à Psicologia e, no Brasil, também ao campo da Educação. Essas áreas estão mais interessadas no impacto dos conteúdos midiáticos no comportamento infantil do que em entender as dinâmicas que envolvem 0 circuito comunicativo dessa produção. Este artigo, em contrapartida, propôs-se a preencher parte dessa lacuna ao se voltar para os fluxos dos desenhos animados pensados para crianças pequeninas, que, embora pouco ainda conheçam do mundo, já estão habituadas a manipular diferentes plataformas e conteúdos midiáticos pensados para elas.

A cultura digital intensificou dois fenômenos aparentemente contraditórios. De um lado, aumentou o potencial de espraiamento das grandes empresas de mídia, sobretudo daquelas vinculadas aos conglomerados midiáticos, as quais, historicamente, dominaram a produção e distribuição dos desenhos na televisão 
ocidental. De outro lado, os últimos anos viram ascender produtores menores que, munidos de softwares e computadores ligados em rede, têm conseguido criar desenhos e manter uma produção sistemática, capaz de suprir demandas consolidadas nas grades televisivas. A proliferação de plataformas audiovisuais, como YouTube e Netflix, permite que parte dessa produção ganhe visibilidade sem necessariamente cumprir os caminhos tradicionais dos conteúdos televisivos.

As consequências mais facilmente constatáveis desse fenômeno são o aumento insólito 1) dos desenhos focados em públicos cada vez mais segmentados, como as crianças até três anos, e 2) das produções locais potencialmente exportáveis para plataformas televisivas ao redor do mundo. 0 Brasil, nesse sentido, tem visto germinar uma produção nunca antes observada de desenhos animados desenvolvidos de forma seriada, que podem ser encontrados tanto nas televisões aberta e por assinatura quanto em novas plataformas, como Netflix, YouTube, Vimeo, Google Play e tantas outras. A Galinha Pintadinha faz parte desse novo contexto e explicita, sobretudo, que não há apenas uma maneira de lidar com esse fenômeno, além de salientar que se trata de um fenômeno processual, historicamente construído por vários agentes. Ademais, para que esse desenho alcance as centenas de milhares de crianças que vem atingindo, é preciso que diversos atores trabalhem em sinergia (ainda que de forma inconsciente), como produtores, plataformas audiovisuais, empresas de licenciamento, estabelecimentos comerciais e, claro, pais e responsáveis que apresentam esse conteúdo para os pequenos.

Há, ainda, consequências menos visíveis, mas igualmente relevantes, que a análise permitiu observar. Não obstante 0 Brasil esteja vivendo 0 crescimento da produção de desenhos que viajam 0 mundo em plataformas variadas, a atuação dos conglomerados midiáticos ainda delimita, em grande medida, a trajetória dessa produção, além de 0 próprio YouTube ter se tornado uma plataforma mainstream (LOBATO, 2016; MAY, 2010). É premente, pois, ter consciência das complexidades envolvidas nessa distribuição e lembrar que o "público-alvo" ainda usa fraldas e tem um lindo sorriso inocente, conquanto já reconheça e crie afetividade com 0 resultado dessa relação. Além disso, o material a que as crianças são expostas, bem como a sua própria exposição, partem de decisões tomadas por atores outros que não elas, mas são elas as mais fortemente impactadas por quaisquer consequências, sejam estas positivas ou negativas.

\section{Referências}

ANDERSON, Chris. A Cauda Longa: do mercado de massa para o mercado de nicho. Rio de Janeiro: Campus, 2006.

ALTERS, Diane F. "We hardly watch that rude, crude show": class and taste in The Simpsons. STABILE, Carol; HARRISON, Mark (orgs.). Prime Time

Animation: Television Animation and American Culture. New York, Routledge, 2003.

BANKS, Jack. Monopoly Television: MTV's quest to control the music. Boulder: Westview Press, 1996. 
BANKS, Jack. Keeping "Abreast" of MTV and Viacom: The Growing Power of a Media Conglomerate. WASKO, Jant (org). A companion to television. Oxford: Blackwell Publishing, 2005.

BARRIERS, Michael. Hollywood cartoons: American Animation in Its Golden Age. Oxford: Oxford University Press, 1999.

B00KER, M. Keith. Drawn to television: Prime-time animation from the Flinstones to Family Guy. Westport, Connecticut, London: Praeger, 2006.

BULCK, Hilde Van den; ENLI, Gunn Sara. Flow under pressure: television schedulling and continuity techniques as victims of media convergence? Television \& New Media. Vol. 15, n. 5, 2013. BURGESS, Jean; GREEN, Joshua. YouTube e a Revolução Digital. São Paulo: Aleph, 2009. GOMES, Andréia Prietro. História da Animação Brasileira. Cena: Centro de Análise do Cinema e do Audiovisual, 2008. Disponível em https://goo.gl/rMv9XN. Acessado em julho de 2017.

GRAY, Jonathan. Show sold separately: promos, spoilers, and other media paratexts. New York e London: New York University Press, 2010.

HASSAN, Ali; DANIYAL, Muhammad. Cartoon Network and its impact on behavior of school going children: a case study of Bahawalpur, Pakistan. International Journal of Management, Economics and Social Sciences. Vol. 2, n. 1, 2013.

HAYNES, Jonathan. What is to be done? Film studies and Nigerian and Ghanaian videos, SAUL, Mahir; AUSTEN, Ralph. Viewing African Cinema in the Twenty-First Century: art films and the Nollywood video revolution. Ohio: Ohio University Press, 2010.

HORROCKS, Roger. Turbulent Television: The New Zealand Experience. Television \& New Media. Vol. 5, n. 1, 2004.

JENKINS, Henry. Cultura da Convergência. São Paulo: Aleph, 2009.
LOBATO, Ramon. The cultural logic of digital intermediaries: YouTube multichannel networks.

Convergence. Vol. 1, n. 13, 2016.

MASSAROL0, João Carlos; MESQUITA, Dario. Video sob demanda: uma nova plataforma televisiva. Trabalho apresentado no Grupo de Trabalho - Estudos de Televisão, do XXV Encontro Anual da Compós, na Universidade Federal de Goiás, Goiânia, de 07 a 10 de junho de 2016.

MAY, Albert. Who Tube? How YouTube's News and Politics Space is Going Mainstream. International Jounal of Press/Politics. Vol. 15, n. 4, 2010.

MITCHELL, Tracey L. "Kid's stuff": television cartoons as mirrors of the American mind. Eric Collection, 1995. Disponível em https://eric.ed.gov/?id=ED386771. Acessado em julho de 2017.

MITTELL, Jason. Cartoon Realism: genre mixing and the cultural life of The Simpsons. The Velvet Light Trap, n. 47, 2001.

MITTELL, Jason. The great Saturday morning exile: Scheduling cartoons on television's periphery in the 1960s. STABILE, Carol; HARRISON, Mark (orgs.).

Prime Time Animation: Television Animation and American Culture. New York, Routledge, 2003.

MITTELL, Jason. Genre and Television: from cops shows to cartoons in American culture. London: Routledge, 2004.

MORREALE, Joanne. From homemade to store bought: Annoying Orange and the Profissionalization of YouTube. Journal of Consumer Culture. Vol. 14, n. 1, 2013.

PEREA, Katia. Girls Cartoon Second Wave: transforming the genre. Animation: An Interdisciplinary Journal. Vol. 10, n. 3, 2015.

PINHO, Maria Luiza Carvallo de Aguiar; ROCHA, Angela da. Bromélia Filminhos e as aventuras internacionais da Galinha Pintadinha. Administração: Ensino e Pesquisa. Vol. 16, n. 3, 2015. 
SAMPAIO, Inês Sílvia Vitorino; CAVALCANTE, Andréa Pinheiro Paiva. Qualidade na programação infantil da TV Brasil. Florianópolis: Editora Insular, 2012.

SANDLER, Kevin S. Synergy Nirvana: Brand equity, television animation, and Cartoon Network. STABILE, Carol; HARRISON, Mark (orgs.). Prime Time

Animation: Television Animation and American

Culture. New York, Routledge, 2003.

SAUL, Mahir; AUSTEN, Ralph. Viewing African

Cinema in the Twenty-First Century: art films and the Nollywood video revolution. Ohio: Ohio University Press, 2010.

SHIFMAN, Limor. An anatomy of a YouTube Meme. New Media \& Society, Vol. 14, n. 2, 2011.

STABILE, Carol; HARRISON, Mark (orgs.). Prime Time Animation: Television Animation and American Culture. New York, Routledge, 2003.

STEWART, Mark. The Myth of Televisual Ubiquity.

Television \& New Media. Vol. 1, n. 15, 2016.

URBANO, Krystal Cortez Luz. Legendar e distribuir: o fandom dos animes e as políticas de mediação fansubber nas redes digitais. Dissertação de mestrado, Programa de Pós-graduação em Comunicação da Universidade Federal Fluminense. 2013

WAISBORD, Silvio. McTV: Understanding the global popularity of television formats. Television \& New Media. Vo.5, n. 4, 2004. 


\section{For small children but big spectators: the made-for-preschool- children Brazilian television production in relation to Lottie Dottie Chicken cartoon}

\section{Abstract}

The TV cartoons aimed at preschoolers are quickly growing over the recent years. This is happening especially because of the popularity of new media environment such as YouTube and Netflix, which are opening new possibilities for television consumption. In Brazil, it is possible to point out many strategies developed by the companies that manage the madefor-preschooler TV cartoons to attract an increasingly audience. This phenomenon has reconfigured madefor-children media circuit and the relation that children maintain with their favorite cartoons. The article gives a brief history of the presence of cartoons on television, with emphasis on the Brazilian context, to analyze then the global flow strategies developed by one of the most famous contemporary Brazilian TV cartoons directed to children up to 3 years: Lottie Dottie Chicken. Then, it is possible to understand the complexity of the circuit involving this type of content and the way in which new platforms such as YouTube help reconfigure the place of children's audiovisual content.

\section{Keywords}

Children's programming. Television cartoons. Lottie Dottie Chicken. YouTube

\section{Para pequeños grandes}

\section{espectadores: la producción}

televisiva brasileña direccionada

\section{a los niños a partir del caso}

\section{de la Gallina Pintadita}

\section{Resumen}

La programación televisiva para niños viene ganando contornos de superproducción recientemente, cuando espacios como YouTube abren nuevas posibilidades de consumo audiovisual. En Brasil, es posible apuntar diversas estrategias desarrolladas por las empresas que gestionan esos contenidos para atraer un número cada vez mayor de público, lo que viene reconfigurando todo el circuito comunicativo de ese contenido. El artículo hace un breve histórico de la presencia de los dibujos en la televisión, con destaque para el contexto brasileño, y analiza las estrategias de transmisión de uno de los más famosos dibujos brasileños dirigidos a niños hasta 3 años: la Gallina Pintadita. Con eso, fue posible entender la complejidad del circuito que involucra ese tipo de contenido y la manera con que las nuevas plataformas, como YouTube, ayudan a reconfigurar el lugar de los contenidos audiovisuales infantiles.

\section{Palabras-clave}

Programación Infantil. Dibujos animados.

Gallina Pintadita. 


\section{Expediente}

A revista E-Compós é a publicação científica em formato eletrônico da Associação Nacional dos Programas de Pós-Graduação em Comunicação (Compós). Lançada em 2004, tem como principal finalidade difundir a produção acadêmica de pesquisadores da área de Comunicação, inseridos em instituições do Brasil e do exterior.

\section{E-COMPÓS I www.e-compos.org.br I E-ISSN 1808-2599}

Revista da Associação Nacional dos Programas de Pós-Graduação em Comunicação. Brasília, v.21, n.2, maio/ago. 2018. A identificação das edições, a partir de 2008, passa a ser volume anual com três números. Indexada por Latindex I www.latindex.unam.mx

\section{CONSELHO EDITORIAL}

Ada Cristina Machado Silveira, Universidade Federal de Santa Maria, Brasil Alda Cristina Silva da Costa, Universidade Federal do Pará, Brasil Alfredo Luiz Paes de Oliveira Suppia, Universidade Estadual de Campinas, Brasil Ana Regina Barros Rego Leal, Universidade Federal do Piauí, Brasil Ana Carolina Rocha Pessôa Temer, Universidade Federal de Goiás, Brasil André Luiz Martins Lemos, Universidade Federal da Bahia, Brasil Angela Cristina Salgueiro Marques, Universidade Federal de Minas Gerais, Brasil Ângela Freire Prysthon, Universidade Federal de Pernambuco, Brasil Anna Cristina Pertierra, Western Sidney University - Australia Antonio Carlos Hohlfeldt, Pontifícia Universidade Católica do Rio Grande do Sul, Brasil Arthur Ituassu, Pontifícia Universidade Católica do Rio de Janeiro, Brasil Bruno Campanella, Universidade Federal Fluminense, Brasil Bushra Rahman, University of the Punjab, Paquistão Cláudio Novaes Pinto Coelho, Faculdade Cásper Líbero, Brasil Cárlida Emerim, Universidade Federal de Santa Catarina, Brasil Carlos Del Valle Rojas, Universidad de La Frontera, Chile Carlos Eduardo Franciscato, Universidade Federal de Sergipe, Brasil Danilo Rothberg, Universidade Estadual Paulista, Brasil Denise Tavares da Silva, Universidade Federal Fluminense, Brasil Diógenes Lycarião, Universidade Federal do Ceará, Brasil Doris Martines Vizcarrondo, Universidad de Porto Rico, Porto Rico Eduardo Vicente, Universidade de São Paulo, Brasil Eliza Bachega Casadei, Escola Superior de Propaganda e Marketing - SP, Brasil Elvira Gomes dos Reis, Universidade do Cabo Verde, Cabo Verde Eneus Trindade, Universidade de São Paulo, Brasil Erick Felinto de Oliveira, Universidade do Estado do Rio de Janeiro, Brasil Erick Torrico, Universidad Andina Simón Bolívar, Bolívia Erly Vieira Júnior, Universidade Federal do Espírito Santo, Brasil Fabio La Rocca, Université Paul Valéry Montpellier III, França Fernando Firmino da Silva, Universidade Federal da Paraíba, Brasil Francisco de Assis, FIAM-FAAM Centro Universitário, Brasil Francisco Elinaldo Teixeira, Universidade Estadual de Campinas, Brasil Francisco Gilson R. Pôrto Jr., Universidade Federal do Tocantins, Brasil Francisco Sierra Caballero, Ciespal, Equador

Frederico de Mello Brandão Tavares, Universidade Federal de Ouro Preto, Brasil Gabriela Reinaldo, Universidade Federal do Ceará, Brasi Gérman Rey, Pontifícia Universidad Javeriana, Colômbia Gilson Vieira Monteiro, Universidade Federal do Amazonas, Brasil Gustavo Daudt Fischer, Universidade do Vale do Rio dos Sinos, Brasil Gustavo Hernández Díaz, Universidad Central de Venezuela, Venezuela Heidi Figueroa Sarriera, Universidad de Puerto Rico, Porto Rico Ignacio Aguaded, Universidad Huelva, Espanha

Inesita Soares de Araújo, FIOCRUZ, Brasil Itania Maria Mota Gomes, Universidade Federal da Bahia, Brasil Jiani Adriana Bonin, Universidade do Vale do Rio dos Sinos, Brasil João Carlos Correia, Universidade de Beira Interior, Portugal Jonathan Cohen, da University of Haifa, Israel José Afonso da Silva Junior, Universidade Federal de Pernambuco, Brasil José Luiz Aidar Prado, Pontifícia Universidade Católica de São Paulo, Brasil Josette Maria Monzani, Universidade Federal de São Carlos, Brasil Juçara Gorski Brittes, Universidade Federal de Ouro Preto, Brasil Julián Durazo Herrmann, Université du Québec à Montréal Juliana Freire Gutmann, Universidade Federal da Bahia, Brasil
Karla Covarrubias, Universidad de Colima, México Laura Loguercio Cánepa, Universidade Anhembi Morumbi, Brasil Leonel Azevedo de Aguiar, Pontifícia Universidade Católica do Rio de Janeiro, Brasi Letícia Cantarela Matheus, Universidade do Estado do Rio de Janeiro, Brasil Ling Chen, Hong Kong Baptist University Luciana Coutinho Souza, Universidade de Sorocaba, Brasil Maria Ataide Malcher, Universidade Federal do Pará, Brasil Maria Elena Hernández Ramírez, Universidad de Guadalajara, México Maria Elisabete Antonioli, Escola Superior de Propaganda e Marketing - SP, Brasil Maria das Graças Pinto Coelho, Universidade Federal do Rio Grande do Norte, Brasil Maria Teresa Quiroz, Universidad de Lima, Peru Marialva Carlos Barbosa, Universidade Federal do Rio de Janeiro, Brasil Marina Poggi, Universidad Nacional de Quilmes, Argentina Marcel Vieira Barreto Silva, Universidade Federal da Paraíba, Brasil Marcia Tondato, Escola Superior de Propaganda e Marketing, Brasil Marli Santos, Universidade Metodista de São Paulo, Brasil Márcio Souza Gonçalves, Universidade do Estado do Rio de Janeiro, Brasil Mateus Yuri Passos, Universidade Metodista de São Paulo, Brasil Mauricio Mario Monteiro, Universidade Anhembi Morumbi, Brasil Mayka Castellano, Universidade Federal Fluminense, Brasil Mirna Varela, Universidad de Buenos Aires, Argentina Mozahir Salomão Bruck, Pontifícia Universidade Católica de Minas Gerais, Brasil Neyla Pardo, Universidad Nacional de Colombia, Colombia Nísia Martins Rosario, Universidade Federal do Rio Grande do Sul, Brasil Olga Guedes Bailey, Nottingham Trent University, Inglaterra Paolo Demuru, Universidade Paulista, Brasil Paolo Peverini, L.O.U.I.S.S de Roma, Itália

Paško Bilić, Institute for Development and International Relations, Croácia Paula Melani Rocha, Universidade Estadual de Ponta Grossa, Brasil Potiguara Mendes Silveira Jr, Universidade Federal de Juiz de Fora, Brasil Priscila Ferreira Perazzo, Universidade Municipal de São Caetano do Sul, Brasil Rafael Cardoso Sampaio, Universidade Federal do Paraná, Brasil Rafael Tassi Teixeira, Universidade Tuiuti do Paraná, Brasil Regiane Lucas Garcês, Universidade Federal de Minas Gerais, Brasil Regiane Regina Ribeiro, Universidade Federal do Paraná, Brasil Renata Pitombo Cidreira, Universidade Federal do Recôncavo da Bahia, Brasil Renato Essenfelder, Escola Superior de Propaganda e Marketing, Brasil Roberto Elísio dos Santos, Universidade Municipal de São Caetano do Sul, Brasil Robson Borges Dias, Universidade Católica de Brasília (UCB), Brasil Rodolfo Rorato Londero, Universidade Estadual de Londrina, Brasil Rosario Sánchez Vilela, Universidad Católica del Uruguay, Uruguai Roseli Figaro, Universidade de São Paulo, Brasil

Saima Saeed, Jamia Millia Islamia, India Sara Brandelero, Leyden University, Holanda

Simone Maria Andrade Pereira de Sá, Universidade Federal Fluminense, Brasil Sônia Caldas Pessoa, Universidade Federal de Minas Gerais, Brasil Sun Sun Lim, Singapore University of Technology and Design, Singapura Tatiana Oliveira Siciliano, Pontifícia Universidade Católica do Rio de Janeiro, Brasil Thaïs de Mendonça Jorge, Universidade de Brasília, Brasil Valquiria Michela John, Universidade Federal do Paraná, Brasil Vicki Mayer, Tulane University, Estados Unidos Yamile Haber Guerra, Universidad de Oriente, Cuba 


\section{CONSELHO CIENTÍFICO}

Cristiane Freitas Gutfreind, Pontifícia Universidade Católica do Rio Grande do Sul, Brasil I Eduardo Antônio de Jesus, Universidade Federal de Minhas Gerais, Brasil | Eduardo Morettin, Universidade de São Paulo, Brasil I Irene de Araújo Machado, Universidade de São Paulo, Brasil | Miriam de Souza Rossini, Universidade Federal do Rio Grande do Sul, Brasil

\section{COMISSÃO EDITORIAL}

Igor Pinto Sacramento, Universidade Federal do Rio de Janeiro, Brasil । Kelly Cristina de Souza Prudencio, Universidade Federal do Paraná, Brasil । Osmar Gonçalves dos Reis Filho, Universidade Federal do Ceará, Brasil | Rafael Grohmann, Faculdade Cásper Líbero, Brasil | Thaiane Moreira de Oliveira, Universidade Federal Fluminense, Brasil (editores associados)

\section{CONSULTORES AD HOC}

Alessandro Constantino Gamo, Universidade Federal de São Carlos (UFSCAR) | Amanda Mauricio Pereira Leite, Universidade Federal do Tocantins (UFT) | Amílcar Almeida Bezerra, Universidade Federal de Pernambuco (UFPE) I Ana Carolina Damboriarena Escosteguy, Universidade Federal de Santa Maria (UFSM) I Ana Luiza Coiro Moraes, Faculdade Cásper Líbero | Antonio Pacca Fatorelli, Universidade Federal do Rio de Janeiro (UFRJ) | Ariane Diniz Holzbach, Universidade Federal Fluminense (UFF) I Benjamin Picado, Universidade Federal Fluminense (UFF) I César Augusto Baio dos Santos, Universidade Federal do Ceará (UFC) I César Geraldo Guimarães, Universidade Federal de MInas Gerais (UFMG) I César Ricardo Siqueira Bolaño, Universidade de Brasília (UNB) I Ciro Marcondes Filho, Universidade de São Paulo (USP) I Felipe Simão Pontes, Universidade Estadual de Ponta Grossa I Felipe Trotta, Universidade Federal Fluminense (UFF) I Gislene da Silva, Universidade Federal de Santa Catarina (UFSC) I Kati Caetano, Universidade Tuiuti do Paraná I Laan Mendes de Barros, Universidade Estadual Paulista Júlio de Mesquita Filho I Lucia Leão, Pontifícia Universidade Católica de São Paulo (PUC-SP) I Jairo Getulio Ferreira, Universidade do Vale do Rio dos Sinos (UNISINOS) | Juliana Doretto, FIAM-FAAM | Juliano Maurício de Carvalho, Universidade Estadual Paulistaa Júlio de Mesquita Filho | Lilian Cristina Monteiro França, Universidade Federal de Sergipe I Liziane Soares Guazina, Universidade de Brasília (UNB) I Luís Mauro Sá Martino, Faculdade Cásper Líbero | Luiz Peres Neto, Escola Superior de Propaganda e Marketing (ESPM) I Herom Vargas, Universidade Metodista de São Paulo I Inês Silvia Vitorino Sampaio, Universidade Federal do Ceará (UFC) I Maria Helena Weber, Universidade Federal do Rio Grande do Sul (UFRGS) I Mariana Baltar, Universidade Federal Fluminense (UFF) I Maurício de Bragança, Universidade Federal Fluminense (UFF) I Mauro de Souza Ventura- Universidade Estadual Paulista Júlio de Mesquita Filho I Muniz Sodre de Araujo Cabral, Universidade Federal do Rio de Janeiro (UFRJ) I Nuno Manna, Universidade Federal da Bahia (UFBA) I Rosana de Lima Soares, Universidade de São Paulo (USP) I Sandra Maria Lúcia Pereira Gonçalves, Universidade Federal do Rio Grande do Sul (UFRGS) I Sérgio Luiz Gadini, Universidade Estadual de Ponta Grossa I Talitha Gomes Ferraz, Escola Superior de Propaganda e Marketing (ESPM) I Victa de Carvalho Pereira da Silva, Universidade Federal do Rio de Janeiro (UFRJ)

\section{EQUIPE TÉCNICA}

ASSISTENTES EDITORIAL Melina Santos | REVISÃO DE TEXTOS Fátima Áli | EDITORAÇ̃̃o ELETRÔNICA Roka Estúdio

COMPÓS I www.compos.org.br

Associação Nacional dos Programas de Pós-Graduação em Comunicação

Presidente

Marco Roxo

Programa de Pós-Graduação em Comunicação - UFF marcos-roxo@uol.com.br

Vice-Presidente

Isaltina Gomes

Programa de Pós-Graduação em Comunicação - UFPE

isaltina@gmail.com

Secretária-Geral

Gisela Castro

Programa de Pós-Graduação em Comunicação

e Práticas de Consumo - ESPM

castro.gisela@gmail.com

CONTATO I revistaecompos@gmail.com 